\title{
Real Projects to involve undergraduate students in CS degrees
}

\author{
Marisa Gil \\ Universitat Politècnica de Catalunya, UPC \\ Barcelona,Spain \\ marisa@ac.upc.edu \\ Roser Cussó \\ Universitat Politècnica de Catalunya, UPC \\ Barcelona,Spain \\ roser.cusso@gmail.com
}

\author{
María-José Fernández \\ Universitat Politècnica de Catalunya, UPC \\ Barcelona,Spain \\ marjo.fernandezmostaza@gmail.com \\ Carlota Crusafon \\ Universitat Politècnica de Catalunya, UPC \\ Barcelona,Spain \\ Carlotacrusafon@gmail.com
}

Abstract - Technological advances are improving the standard of
living and working conditions. Curiously, the number of students
that choose technological studies and careers continues to decline. that choose technological studies and careers continues to
This fall is particularly noteworthy in respect of females.

One of the main reasons for this is that neither the model of professional profile promoted, nor the global approach of the mission is attractive or appealing.

Some studies indicate that problem-based and project-based learning methods are conducive not only to acquiring social and interpersonal skills that are valuable in a workplace, but also to increasing gender diversity in engineering degrees [9].

In this paper we present a pilot project, ICT4Girls. The main goal is to diffuse computer science as a real tool for service of society, with a principal aim of promoting ICT careers.

Based on a wireless sensor network (WSN) platform, several real projects by undergraduate students are presented. For our purposes here, two projects have been defined. Beginning from a basic-skill framework, each presents a different audience and goals.

Computer Science, technical skills, Profession, Real-world Project

\section{INTRODUCTION}

The lack of technological vocations is a reality in undergraduate studies as well as in professional careers [1]. This is particularly noteworthy in respect of females

One of the main reasons for this points to the lack of knowledge of the professional profile in the computer science field [2]. Teenagers and undergraduates do not have clear models in their lives (neither real people nor fictional characters). Consequently they do not know the kind of job an IT professional performs, and do not pursue the corresponding degrees (Computer Science and Computing Engineering) as an option relevant to their future career.
One possible solution to this problem may be to introduce a real project in the curriculum: describing a problem, devising a specific solution and making the implementation in a real platform.

Choosing a people-centric project to improve their own community (school, neighbourhood, shopping-mall) they will become familiar with the social aspects of their future job. This aspect is a fundamental part of making Computer Science appealing to new generations: to appreciate the tangible improvements that transpire from their own technical work for both the environment and the people.

These project-based classes also have the advantage of allowing the student to develop other professional skills such as leadership, teamwork and decision making analysis.

Similarly, they offer scope to learn and improve technical skills such as modular and parallel programming, event management or testing experiment design, as well as new areas of interest including open source software, low power analysis and mobility.

With this in mind we present a foundation to develop real projects based on a wireless sensor network (WSN) platform and two project proposals presented by undergraduate students [3].

The rest of the document is organised in the following way: in the next section, we describe the project goals and introduce our project-based proposal. In the third section, we introduce the basic platform to develop our framework. In section four we present our methodology and two current projects, each with different characteristics and requirements. Section five presents some related work in the project-based learning methodology field. Finally, section six deals with the conclusions and future work.

This work is supported by the HiPEAC European NoE, the Ministry of Science and Technology of Spain and the European Union (FEDER) under contract TIN2007-60625 and TIN2009-07333-E/TSI, and by the Generalitat de Catalunya (2009-SGR-980)) 


\section{OUR PROJECT-BASED LEARNING APPROACH}

There are well-known references and experiences [9][12] which show project-based learning to be a methodology that connects better with the skills required by employers and encourages the recruitment of more women engineering students [9]. The research in the area shows that learning is a rich context of experiences, not only based on abstract information, but on the exchange of this through hands-on experiments, social activities, community discussions, and real problem solving, among other forums.

The main concerns when designing these types of courses are 1) how to link them with other previous courses; 2) how to use the course to learn specific social and other transferable skills and 3) how to acquire the desired technical and science skills.

The choice of the platform and environment used to build the project is as important as determining the objectives and methodology to accomplish all of these three goals. This platform should allow for a variety of situations to promote creativity, acquire professional habits and attitudes, and to improve their comprehension in computing, among other goals.

Another important point for this choice was that secondary students already had familiarity with these devices (sensors, network issues, etc), so they were able to share experiences and even participate in the projects with undergraduate students.

In this project, we have chosen a wireless sensor network platform and the activities have been designed jointly with a technological enterprise DEXMA, http:www.dexmatech.com, which provides professional expertise and advice on the appropriate devices. They are also in charge of introductory seminars.

To initiate the activity, we engaged a reduced team of female students to participate in a program to introduce secondary female students to ICT careers. In this program there were two main activities:

- $\quad$ To present a set of solutions to current problems using well-known technology and devices;

- $\quad$ To introduce personal experiences of undergraduate life on Campus.

From these activities, we had the beginnings of the first project, in which both undergraduates and secondary students participated (see 4.1).
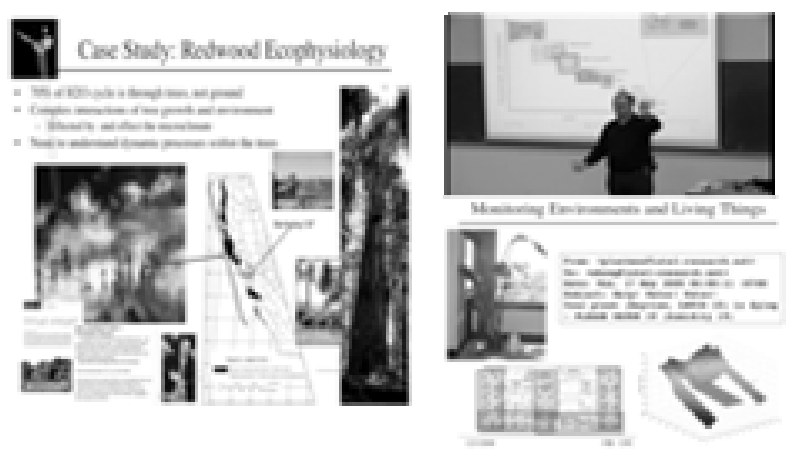

Fig. 1. Introducing technology and familiar devices to manage real current problems.

\section{A. $\quad$ Link with previous courses}

A main goal in project-based learning (PBL) is to improve usability, deeper element knowledge and a more mature relationship between different subjects, already done.

In our case, the sensors are programmed in a specific C-like language -nesC- based on events, the servers that receive data are programmed in $\mathrm{C}++$ or Java, and user applications can be programmed in more user-friendly web or graphic-based languages. In addition, scripts that act as glue for the different parts of a complete application should be written in python.

Programming language requisites are covered in lower-level courses for students of Computer Science, as well as Computer Architecture and Network Systems introductory courses.

Some other courses such as graph theory, statistics and other mathematical topics are also interesting and can improve the project results.

Obviously, depending on students' background, the project definition and goals must be adapted.

\section{B. Social habits and attitudes}

The European Parliament and the Council of the European Union defines key competences as “...those which all individuals need for personal fulfillment and development, active citizenship, social inclusion and employment. By the end of initial education and training young people should have developed the key competences to a level that equips them for adult life, and they should be further developed, maintained and updated as part of lifelong learning" [8]. And it sets out 8 key competences:

- Communication in the mother tongue;

- Communication in a foreign language;

- Mathematical competence and basic competences in science and technology

- Digital competence;

- $\quad$ Learning to learn;

- Interpersonal, intercultural and social competences and civic competence;

- Entrepreneurship; and 


\section{- Cultural expression.}

The last three competences are qualitative, personal and subjective skills more related with personal attitudes such as willingness to listen to, to look at, to discover the needs of the other. Being capable of interacting with the resources, using the technology to make a more comfortable, more sustainable world, and to facilitate and to improve the quality of life of people, offering specific services - these are all skills which will be addressed in different ways by the projects we propose.

Engineering education should promote "habits of mind" 1 aligned with what many believe are essential skills for citizens in the $21 \mathrm{st}$ century. These include systematic thinking, creativity, optimism, collaboration, communication and attention to ethical considerations [10]

In engineering areas employers seek "people persons"people who not only have technical knowledge and technical skills, but those who also have interest in the human needs and environmental issues [9].

"The engineer of 2020: visions of engineering in the new century ", [11], takes these aspirations a step further in chapter 4 by setting forth the attributes that will be needed by the graduates of 2020. These include strong analytical skills, creativity, ingenuity, professionalism, and leadership.

The environment where the projects are carried out is the Campus of UPC with the university community acting as "the society". The applications chosen to work on come from the community's needs and research work on the community's style of life. In this way, students also have to learn to communicate with the user (listen to and understand the real needs, establish feedback channels to make progress, decide the best user-application interface, etc.).

Specific examples of the social and communication skills (potentially) included in each project will be considered in a separated paragraph when explaining the respective project. Again, depending on the skills targeted, the basic model of a project can be modified to suit.

\section{Technical skills}

PBL courses assume that main technical skills are already acquired [7] in the previous courses, as see in section 2.1. With their technical skills, students have to manage the different programming models and network connection programmability; decide the communication model to use (master-slave, pervasive, mesh connection); propose the data structures to keep information; design the user-interfaces to input/output information, etc.

However, some specific tools should be provided to help participants apply their (often rather generic) skills to a real situation with very specific demands. In our referenced

\footnotetext{
${ }^{1}$ The committee has adopted the term "habits of mind", as used by the American Association for the Advancement of Science in Science for All Americans (1990) to refer to the values, attitudes, and thinking skills associated with engineering.
}

projects, these tools include the following two examples. First, a weekly seminar to introduce students to how-to-do issues: system configuration and setup, application examples, etc. Two of these seminars were organized by DEXMA. Second, a twice-monthly team brainstorming session to share the experiences and work done by each team member and to propose new applications and services to develop.

\section{A WSN FRAMEWORK FOR USE IN PROJECTS}

The technological basis for the project is a pervasive and ubiquitous platform with wireless sensor networks (WSN) to collect data. This data should allow for the development of different applications to improve the site and to make it more user-friendly.

Our first location is a University Campus (Campus Nord in UPC). The sensors capture temperature, luminity and presence to be processed in different ways by the various proposed applications. There will be some servers distributed throughout the Campus to collect and manage data. End users will connect via wireless to different applications depending on the information needed. Data connexion will be through the Campus wireless service, via intranet. In this way we can guarantee security and privacy in accessing the data.

Different sensor distribution in the area can restrict the different configurations to collect data. So, depending on whether there is a master reading all of the information or the information is based on a "multi-hop" style, some decisions have to be taken about network connections.

This general framework, with minor modifications, can be adapted to different contexts; for example a shopping mall, a school or a neighbourhood.

Once the infrastructure to work on is decided, we have to consider other aspects:

1. How to introduce students to programming WSN. A weekly seminar.

2. How to express the "social skills" as demanded by the European Parliament (last three on the list above).

3. Which applications are most suitable to develop. To do this students have their own meetings, brainstorming with other classmates, and sharing information from related projects and papers.

Starting from the basic platform, the applications will be proposed by the students, following one of two main models:

A. Energy-saving oriented: in this case, the information given is more general, related to resource use such as lighting or heating. It can be used to promote sustainability and power management in everyday personal and working activities.

B. Service oriented: the information provided is used to give specific services the users require on demand.

In the next section we explain the general methodology we follow in the projects and we present a representative example for each one of the application models: a monitoring application and a parking alarm. 
IV.

PROJECT BASED LEARNING METHODOLOGY

PBL is based on contextualized content. Usually the teacher works with a case that would have been real originally but it has no real-world immediacy for the students, and they consequently fail to engage with it. Additionally, these relatively abstract problems may or may not eventually arise in the real world. This can also dampen students' enthusiasm for fully applying themselves to the task.

For us it is very important the student detects the problem and looks for a solution: the student's role is active and allows for the developing of two basic competences in the entrepreneurial world. The first is to translate the user needs into technical words; the second, to work with different disciplines if necessary.

\section{A. Firs project: Maximizing energy efficiency}

This is a real project lead by students in collaboration with a technological enterprise, DEXMA [4]. The goal of this project is to sensitize people to energy saving by improving their habits in lighting and heating.

With this project we want to acquire not only technical skills, but also skills like the concern for human needs and environmental issues.

From the initial WSN platform deployed throughout the Campus, we monitor the temperature at different points to be able to quantify the energy we waste. This data collected will be the basis for an application - called AmbientReader- that allows us to measure the energy wastage and then propose different solutions [5].

For example, we measure the temperature in a classroom. A temperature higher than $21^{\circ} \mathrm{C}$ when the room is full means that the place is overheated, so energy is wasted.

Steps to follow:

1. Characterization of the place to study. The study is done in the classroom buildings (see Fig. 1). First, we need to determine the temperature characteristics to take into account, For example, whether or not there are variations depending on the floor level, the orientation (north, south, east, and west), the time of the day, or the amount of people inside the room. The goals in this step are:

- To choose the most suitable position to place the WSN (ends of Campus, ends of each building, different floors);

- To measure the temperature changes depending on the classroom being in use or not (full or empty rooms);

- To measure how the temperature changes based on the time of the day (morning, noon, evening).

2. Evaluation of the fine tuning. The turning-on and turning-off of the heating needs time and has an associated delay which we can estimate as a constant value, so we will determine if it makes sense to stop or reduce the heating and for how much time do so. The goals in this step are:
- To calculate the time and temperature at which to turn on heating;

- To combine the two influences on temperature, the ambient and the dedicated, to maintain the temperature within the range of comfort.

This project is a practical example of technology being socially relevant [6].

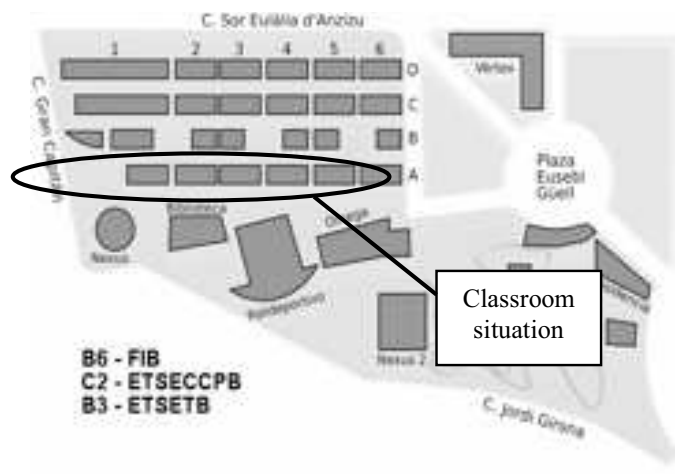

Fig. 2. Campus Nord map remarking the classroom situation, at South

\section{B. $\quad$ Second project: Friendly parking}

The second project also contributes to a friendly environment in that it helps to decrease $\mathrm{CO} 2$ emissions, but the main focus is more clearly customer-centred. The aim to facilitate parking is a real client need.

In this case, the proposal was born on the initiative of a participant to improve Campus services after having heard some user comments.

Campus Nord has a parking facility for the University community with 190 locations. The car park works as follows:

There is a single-direction traffic flow, so cars enter by one street (Sor Eulalia d'Anzizu) and exit by the opposite (Gran Capità).

If a car can't find a place, other cars might have their exit impeded; also there is a lot of waste in time and gas while looking for a parking.

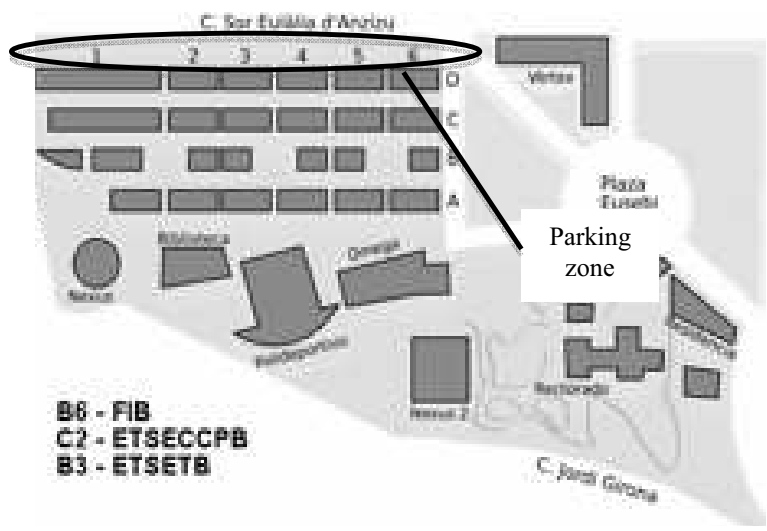

Fig 3. Campus Nord map remarking the parking part, at North 
The goal of this project is monitoring car parking to inform users when a place becomes free and where this free place is. When a space becomes free, the application will send a notification, via e-mail or sms. In addition it is possible to visualize the map with the exact places free in real time

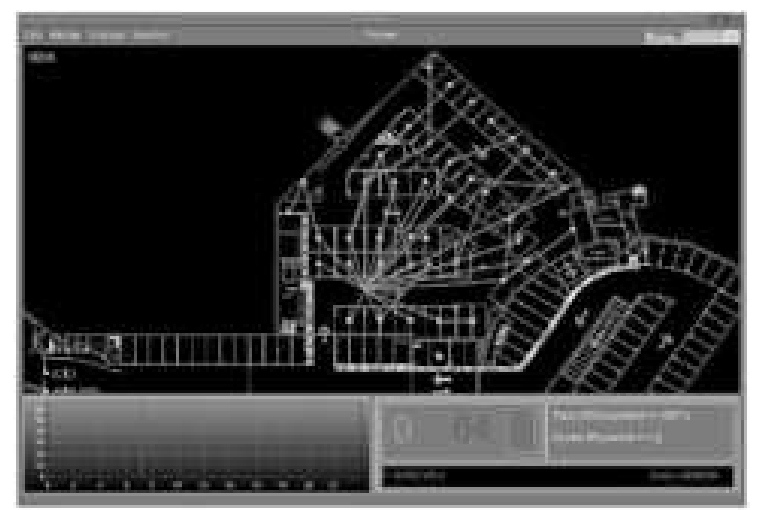

Fig. 4. An exemple of a mesh connection map

Again, the technical basis is a WSN with a sensor in each of the car spaces. The electronic device (mote) works with batteries, is able to detect the presence of a car and broadcast the information up to $70 \mathrm{~m}$. to other devices. All devices form a mesh monitoring all the places in real time and communicate with the server, which manages information and offers a set of services to the users.

When a driver arrives to the Campus, if there is no parking he/her will notify the fact to the server (via mail, sms or web). The server has a specific policy to schedule demands, as it might be chaotic if all clients received a free-place notification at the same time.

A position map can be consulted from home or from the mobile phone, so it is possible to select different ways to reach the Campus. A warning system can be added.

This example has different levels of work, and students might be oriented just to one or combine several, in different teams, or courses, even course-level, depending on their background. For example, there is a very interesting study on the user-side: how to present the information, in which interface, how to warn (e-mail, sms, etc),... On the other hand, the technical concerns are also, very appealing and can be managed in different ways of expertise: how to detect a free place (automatically when the car goes or the car proprietary sends a message, etc), and so on.

\section{RELATED WORK}

There is a 2007 work from University of Waikato (New Zeland) [12]. In contrast to our proposal, the guidelines of the Waikato project are more rigid, the ends are more abstract, having no final application in the University community, and consequently this may appeal less to females.

Other PBL works are based on playing a role like the EnROLE project [13]. In this case, students and teachers play a role representing users, clients, businesspeople, etc. Again, in our proposal these roles are real and not imagined. The authenticity of the roles in our scheme makes the experience more "immediate" for the participant, and provides a more stimulating and rewarding learning environment.

Maybe the most comparable work is the Open Ended Project [7]. We differ from OEGP in the framework and how it will be established to set up the project, and also in the problem definition itself. Our priority is to produce a practical solution to a real-world problem, defining this solution through close communication with the "end-user".

Additionally, in this paper we present types of project that are suitable due to the skills they provide to students, while the OEGP approach looks for a specific course, with objectives, requirements, and so on.

\section{CONCLUSIONS AND FUTURE WORK}

In this paper, we introduce two real projects to be used in PBL classes. This methodology "with more contextualised content resulted in an increased recruitment of women along with a substantial level of appreciation of learning" [9].

Reflecting on social contributions by their own profession improves students disposition toward technical careers. Additionally, the enthusiasm to contribute to their own community fuels the development of accomplished professionals.

On the side of the community, an increased awareness of the contribution of engineers and IT specialists leads to a more positive vision and higher valuation of these professions.

These two positive streams help create a virtuous circle.

Additionally, the technical platform for the projects (WSN) aims to introduce courses related with these subjects to allow students to acquire competence in these new future areas. Development solutions for the future involve the integration of mobiles with other IT as a usual scenario.

As explained above, our pilot projects have been developed as collaboration between undergraduates and high school students. The main goal was to engage females in ICT degrees, by becoming more familiar with the kind of work that is being developed in these areas. Although this is an ongoing experience, we have already received positive comments and reactions:

1. We have a positive influence on people's vision and behaviour regarding to technology, promoting personal and professional attitudes. For example:

- Fostering interdisciplinary dialog channels between people -students, teachers, and professionals-.

- Incentivize research into low-power high-tech (specialized processors, optimized code, power measurement tools, etc.).

2. We have collaborated with secondary school research projects:

- A team is implementing a similar project using a simpler, well-known technology in their own school; 
- A student is using the same platform to monitor her home with its different climatization conditions (air conditioning, fan or blinds).

The approach we present will be also used as WSN handson material in laboratory courses, or along the degree in several courses.

Other future students' proposed applications are:

- To confirm whether or not a room is in use.

- To know in which of the bars on Campus there is a free table.

- To know if there is a free table in the Campus library.

In a more advanced phase, we plan to include also the participation of Electronic Engineering students to develop new hardware and sensors, as well as collaborate with other degrees to work in multidisciplinary teams.

\section{ACKNOWLEDGMENT}

We sincerely thank Nuria Carcelle, Georgina Punsoda, Marta Jimenez, Albert Franzi and Nacho Navarro, members of ICT4Girls project, and the anonymous reviewers for their comments and suggestions. We also acknowledge the support of the BSC (Barcelona Supercomputing Centre).

\section{REFERENCES}

[1] R. Rashid, Inspiring a New Generation of Computer Scientists. Communications of the ACM Vol. 51, Num.7 (2008)
[2] A. Sellen et al. Reflecting Human Values in the Digital Age Communications of the ACM Vol. 52, Num. 3 (2009)

[3] T. Hammel et al. A Higher Capability Sensor Node Platform Suitable for Demanding Applications. International Conference on Information Processing in Sensor Networks (IPSN) Cambridge, MASS. (2007).

[4] N. Carcelle et al. Listening around you! Wireless Sensor Networks for the saving of energy in the Campus. (In Catalan) International Conference on Information Processing in Sensor Networks (IPSN) Cambridge, MASS. (2007).

[5] M. Buckley Computing as Social Science. Communications of the ACM Vol. 52, Num. 4 (2009).

[6] B. Haberman et al. Making the Computing Professional Domain More Attractive: an Outreach Program for Prospective Students. Int. J. Engng Ed. Vol. 25, No. 3, pp. 534-546 (2009).

[7] M. Daniels et al. Open Ended Group Projects, Motivating Students and Preparing them for the "Real World". Proceedings of the 15th Conference on Software Engineering Education and Training (2002).

[8] Proposal for a recommendation of the European Parliament and of the Council on key competences for lifelong learning. Brussels, 10.11.2005 COM (2005) 548 final. 2005/0221 (COD).

[9] X. Du and Kolmos, A. Increasing the Diversity of Engineering education - A Gender Analysis in a PBL context. European Journal of Engineering Educations Vol. 34, Num.5, pp. 425-437 (2009).

[10] L. Katehiet al. Engineering in K-12 Education. Comittee on K-12 Engineering Education. National Academy of Engineering and National Research Council. ISBN: 978-0-309-13778-2

[11] The Engineer of 2020: Visions of Engineering in the New Century. National Academy of Engineering. ISBN: 978-0-309-09162-6.

[12] Anderson, T. et al. Experience with Practical Project Based Learning in a Developing Undergraduate Engineering Degree Program. International Conference on Engineering Education (ICEE 2007), Coimbra (2007). 